\title{
Non-Coding Genome, Transcription Factors, and Sex Determination
}

\author{
Francis Poulat \\ Institute of Human Genetics, CNRS UMR9002 University of Montpellier, Montpellier, France
}

\section{Keywords}

DMRT1 · FOXL2 · Gonadal development · SOX9·SRY

\begin{abstract}
In vertebrates, gonadal sex determination is the process by which transcription factors drive the choice between the testicular and ovarian identity of undifferentiated somatic progenitors through activation of 2 different transcriptional programs. Studies in animal models suggest that sex determination always involves sex-specific transcription factors that activate or repress sex-specific genes. These transcription factors control their target genes by recognizing their regulatory elements in the non-coding genome and their binding motifs within their DNA sequence. In the last 20 years, the development of genomic approaches that allow identifying all the genomic targets of a transcription factor in eukaryotic cells gave the opportunity to globally understand the function of the nuclear proteins that control complex genetic programs. Here, the major transcription factors involved in male and female vertebrate sex determination and the genomic profiling data of mouse gonads that contributed to deciphering their transcriptional regulation role will be reviewed.

(c) 2021 S. Karger AG, Basel
\end{abstract}

\section{Introduction}

In most eukaryotes, and especially in vertebrates, the genome contains protein-encoding genes separated by non-coding DNA regions that can be very large. The emergence of powerful sequencing techniques showed that the non-coding genome includes significant amounts of non-coding RNA genes whose functions are discussed elsewhere in this issue. Overall, a significant part of the DNA (variable among species) is not transcribed by RNA polymerases. The discovery in the 1980s of "enhancers" (i.e., gene regulatory sequences located distantly from the gene transcription start site) allowed assigning a crucial function to a small fraction of the non-coding genome [Klemm et al., 2019; Andersson and Sandelin, 2020]. The most recent sequencing techniques demonstrated that enhancer sequences also are transcribed, but the function of this transcription is still not fully understood [Sartorelli and Lauberth, 2020]. In parallel, the accumulation of knowledge on the many families of transcription factors (TF) present in eukaryotes brought insights into the relationship between TFs and enhancer-type regulatory sequences.

Correspondence to:

Francis Poulat, francis.poulat@igh.cnrs.fr 
TFs are major effectors of enhancers located in the non-coding genome: they can activate or repress the neighboring genes by binding to specific enhancer sequences. One gene can have distinct enhancers, thus allowing tissue-specific regulation by different TF sets. It can also have several enhancers with redundant activity in a cell type, but with different efficiency. These regulatory elements are called "shadow enhancers" and might be used to control key developmental genes [Kvon et al., 2021]. Enhancer regions can be located within gene bodies, more frequently in introns than in exons, and sometimes also in the $3^{\prime}$ untranslated region. In addition to enhancers located far from the transcription start site, TFs can bind to sequences near or within the promoter region and induce the activation of tissue-specific genes without requiring a complex network of regulatory elements.

Apart from the telomeric and centromeric repeats that contribute to the chromosome physiology, significant amounts of repeated sequences are present in the noncoding genome, resulting from the insertion of transposable elements during evolution [Platt et al., 2018]. In the genome, transposons must be repressed due to their potential toxicity; however, they can be domesticated by the host organism, thus representing a source of new regulatory elements of genes and contributing to the species evolution by creating new enhancers [Garcia-Perez et al., 2016]. The influence of transposon insertion in sex determination has been described in vertebrates, for instance in the teleost fish Oryzias latipes. After duplication of the $d m r t 1$ gene, insertion of transposons upstream of the $d m r t 1 b$ gene changed its regulation by providing new TF binding motifs and gave it the function of a master sexdetermining gene $\left(d_{m r t 1 b Y}\right)$ [Herpin et al., 2010], thus contributing to the appearance of the $\mathrm{Y}$ chromosome.

TFs are among the privileged interlocutors of the noncoding eukaryote genome where they recognize and control the regulatory regions of their target genes. However, individually, TFs display a rather low selectivity for the DNA sequence they recognize: rarely $>20$ nucleotide long and very widely represented in the genome (in total several billion nucleotides). The targeting specificity comes from TF combinations that by interacting in concert drastically increase the sequence recognition stringency. A classic example of this interaction is the synergy between SOX2 and OCT3/4 for the activation of the FGF4 gene [Yuan et al., 1995]. Research on TFs has revealed an immense number of combinations, thus making possible the specific recognition by specific TFs of the very short regulatory sequences of genes. In this review, it will be shown that sex determination, which is controlled by well-characterized TFs in mammals, is a model of choice to study the control of genetic programs by TFs via their interaction with the non-coding genome.

\section{Sex Determination in Vertebrates}

Gonadal sex determination is the process of choosing between 2 transcriptional programs that lead to the establishment of 2 different cell fates, roughly called "testicular" and "ovarian". This process occurs in the embryonic gonads. Gonadal sex determination in mammals, and possibly in other vertebrates, takes place in the progenitors of the embryonic gonad supporting cells that will surround the germ cells. These somatic cells, called the supporting cell precursors, are initially bipotential, and after sex determination, they instruct the germ cells to initiate the process of male or female gametogenesis. In the male gonad, supporting cells are called Sertoli cells, and they form most of the somatic compartment of the future seminiferous tubules. In the female gonad, supporting cells are called granulosa cells, and they gradually organize to form follicular structures that are very different from seminiferous tubules and in which female gametes will be cyclically produced during adult life.

Two major sex determination (SD) mechanisms exist in the animal kingdom: genetic sex determination (GSD) and environmental sex determination (ESD). Both mechanisms target the supporting cell lineage. GSD is based on 2 types of sex chromosomes: (i) the XY/XX system in which males are the heterogametic sex (XY), and (ii) the ZZ/ZW system, where females are the heterogametic sex (ZW) [Hirst et al., 2018]. ESD is based on environmental features, particularly temperature (TSD) [Capel, 2017], but also population density, nutrient availability, or behaviors. Interestingly, in several vertebrates, the 2 mechanisms (GSD and ESD) co-exist [Holleley et al., 2015].

In GSD, the initial trigger is carried by the sex chromosome, and the genes involved in the "testicular" and "ovarian" programs are disseminated throughout the genome, because they are also involved in other developmental programs. Therefore, a precise mechanism of transcriptional regulation is required to discriminate between sex-specific genes (i.e., differentially expressed between sexes). However, a model based only on the activation of the testicular or ovarian program is too simplistic. Experimental data suggest that for each sex, the activation of one program is accompanied by the active repression of the opposing sex program. Studies in the mouse al- 
lowed generating a model where before sex determination, the pro-testicular FGF9 and pro-ovarian WNT-Bcatenin signaling networks are both active in the undifferentiated embryonic gonad [Kim et al., 2006]. Conversely, after sex determination, these 2 pathways become mutually exclusive. FGF9 activation promotes the differentiation of testicular Sertoli cells and maintains the expression of SOX9, whereas the WNT pathway allows the expression of FOXL2 necessary for pregranulosa cell differentiation.

In mammals, the SRY gene on the Y chromosome tips the balance in favor of the testicular program [Koopman et al., 1991], whereas in birds, the Dmrt1 gene on the Z chromosome induces the testicular pathway [Smith et al., 2009; Ioannidis et al., 2021]. In other vertebrates, other GSD mechanisms have been described, involving signaling molecules of the TGF- $\beta$ pathway $(\mathrm{AMH}$, GDF6, GSDF), but they are still poorly understood and will not be detailed here [for a review, see Pan et al., 2021].

In ESD, particularly TSD, the initial temperature-sensitive molecular mechanism has been a black box for a long time, and the underlying mechanism was first described in the red-eared slider turtle Trachemys scripta elegans [Yao et al., 2004; Czerwinski et al., 2016]. Briefly, the initial signal at the female permissive temperature is the mobilization of a calcium flux that initiates the phosphorylation of the TF STAT3 [Weber et al., 2020]. Then, phosphorylated STAT3 represses KDM6B that is required for inducing Dmrt1 expression [Ge et al., 2018]. DMRT1 induces the activation of the testicular pathway [Ge et al., 2017]. Therefore, in T. scripta elegans, the TSD system is controlling the expression of the master gene Dmrt1, similarly to the GSD system used by birds and many other vertebrates.

Although the sex determination mechanism varies in vertebrates, ultimately the result of the "testicular choice" is the expression of $D M R T 1$ in many vertebrates or of $S R Y$ in mammals. At the genome level, the activation of testicular or ovarian genes requires the presence of binding motifs for the ad hoc factors in their regulatory regions (enhancers or promoters). Chromatin immunoprecipitation (ChIP) experiments of testicular (SOX9) and ovarian (FOXL2) TFs showed that these theoretically sex-specific TFs have common targets, suggesting that each can activate sex-specific genes and repress those of the opposite sex (see below). This is in good agreement with the model in the mouse where the FGF and WNT pathways are mutually exclusive [Kim and Capel, 2006]. This mode of regulation requires the specialization of specific enhancer regions that should be active only in the gonad. This is the

Transcription Factor and Sex

Determination case, for example, of the TESCO enhancer of the Sox 9 gene [Sekido and Lovell-Badge, 2008] that in DNase sequencing experiments (a method used to identify accessible chromatin sites), is detected only in the gonad supporting cells and not in other tissues [Maatouk et al., 2017]. This suggests that sex-specific regulatory elements have accumulated binding motifs for the TFs that regulate the testicular and ovarian pathways.

In other cases, the promoter region proximal to the transcription start site provides a tight regulation. For instance, in mammals, the regulation of $A M H$ gene expression (detected in the undifferentiated fetal gonad, and then only in the male gonad up to puberty) requires only a relatively small proximal promoter [Lasala et al., 2004].

This review will mainly describe genomic studies of regulatory mechanisms in mammals.

\section{Transcription Factors Controlling Sex Determination in Mammals Identified by Genetic Studies in Humans}

\section{Transcription Factors Involved in Male Sex \\ Determination}

As TFs are generally weakly expressed, the discovery of their implication in sex determination would have been almost impossible without the contribution of genetic studies, particularly in humans. Indeed, the study of patients with disorders/differences of sex development (DSD) allowed discovering most of the TFs that control sex determination in vertebrates. The discovery of SRY [Gubbay et al., 1990; Sinclair et al., 1990], the Y chromosome-encoded mammalian testis determining factor, accelerated knowledge in this field by providing an entry point into the genetic cascade of which SRY is the initiator.

Then, other TFs encoded by autosomal genes were isolated by studying patients with DSD: SOX9 [Wagner et al., 1994], NR5A1 (also known as SF1) [Achermann et al., 1999], WT1 [Pelletier et al., 1991; Barbaux et al., 1997], DAX1 (or NR0B1) [Swain et al., 1996], and DMRT1 [Raymond et al., 1998].

Loss of function alterations of the SRY coding sequence induce feminization of XY individuals [Berta et al., 1990]. Most SRY mutations are located in the most conserved domain of the protein: the DNA-binding domain, known as high mobility group (HMG) domain. This usually results in the loss of DNA-binding capacity and in the inability to regulate the target genes [Harley et al., 1992]. Moreover, the HMG domain of SRY and of SOX proteins can bend the DNA to which it attaches. 
Some SRY mutations that induce 46,XY DSD can affect this HMG domain feature, thus emphasizing the architectural role of SRY at the chromatin level [Pontiggia et al., 1994]. Finally, mutations in the N- and C-terminal domains of SRY, outside the HMG domain, demonstrated the importance of its interaction with other proteins necessary for its function [Knower et al., 2003].

Heterozygous loss-of-function mutations of SOX9 cause a skeletal defect syndrome (campomelic dysplasia) associated with 46,XY DSD in 75\% of patients ([Houston et al., 1983; Foster et al., 1994; Wagner et al., 1994; Vining et al., 2021]. Most SOX9 point mutations observed in these patients are either located in the HMG domain and alter the DNA binding/bending and/or nuclear translocation [McDowall et al., 1999; Argentaro et al., 2003] or in the C-terminal domain and lead to its truncation with a loss of its trans-activating activity [Sudbeck et al., 1996], suggesting a dominant negative effect of the resulting protein. Conversely, SOX9 duplication causes 46,XX DSD [Huang et al., 1999] in humans, similarly to what observed in gain-of-function experiments in the mouse [Vidal et al., 2001], showing that SOX9 has a dominant effect in testis formation. Interestingly, 2 other SOX genes of the sub-group E have a role in human DSDs: SOX10, which is duplicated in 46,XX DSD (gain of function) [Polanco et al., 2010], and SOX8 point mutations involved in $46, \mathrm{XY}$ DSD (loss of function) [Portnoi et al., 2018]. In mouse fetal testes, Sox 10 is expressed after Sox9 [Polanco et al., 2010]. Moreover, its protein expression profile is very similar to that of $\mathrm{SOX} 9$ in mouse fetal testes, suggesting that it can fully replace SOX9 in testis differentiation. Sox 8 also is expressed in mouse fetal testes after Sox 9 but is a less strong trans-activator than SOX9 [Schepers et al., 2003] and acts in concert with SOX9 for Sertoli cell maintenance in the mouse [Barrionuevo et al., 2016]. The phenotypes observed in patients with DSD highlight a more pronounced role of these 2 genes in sex determination in humans [Portnoi et al., 2018].

The role of NR5A1 (also known as SF1 or Ad4BP) in sex determination might be more complex. The first patients with DSD linked to NR5A 1 mutations were XY individuals with sex reversal [Achermann et al., 1999]. However, many studies have then described a masculinizing role in XX patients with a mutation in SF1 [McElreavey and Achermann, 2017]. For example, in the same family, the SF1 Arg92Trp mutation induced masculinization of an XX individual and feminization of an XY individual [Bashamboo et al., 2016]. The loss of the DNAbinding capacity of the mutated SF1 protein might lead to disruption of signaling pathways, particularly the $\beta$-catenin pathway in the female gonad, as shown by in vitro experiments.

A similar situation was observed for the zinc finger TF WT1: its haploinsufficiency causes the WAGR syndrome, and specific variants cause rare syndromes, such as the Denys-Drash syndrome (variant in zinc finger 2 and 3) [Pelletier et al., 1991] and Frasier's syndrome (splicing variant) [Barbaux et al., 1997]. In these syndromes, XY patients present significant sexual ambiguities and kidney problems. Recently, pathogenic variants in zinc finger 4 of WT1 have been discovered in XX patients with variable levels of testis development. Although the WT1 Arg495Gly variant can still bind DNA, its biological activity is altered towards a gain of function, as indicated by its ability to activate testicular genes. In transgenic mice, this mutation also induces ovary masculinization by partially inducing Sox 9 expression and by strongly reducing Foxl2 expression [Eozenou et al., 2020]. It would be particularly informative to study the genomic targets of this WT1 variant in the embryonic gonad.

DMRT1 is unique as it was first discovered in Drosophila melanogaster (Doublesex, Dsx) and Caenorhabditis elegans (mab-3), and its role in vertebrate sex determination was suggested by its location on human chromosome 9p [Raymond et al., 1998], a region deleted in few $46, X Y$ patients with DSD [Veitia et al., 1997]. It was then reported that the DMRT1 gene is located on the $\mathrm{Z}$ chromosome in chickens [Nanda et al., 1999], suggesting a potential function in sex determination [Raymond et al., 1999]. Therefore, DM domain-containing genes were the first common point between the vertebrate and invertebrate sex-determining systems. Recently, a heterozygous DMRT1 mutation (R111G) [Murphy et al., 2015] was described as causative of XY DSD. This mutation alters the interaction with DNA. As DMRT1 can form multimers of up to 4 proteins, this mutation has a dominant negative effect. This point mutation confirmed that DMRT1 is involved in human sex determination, although its deletion in the mouse does not induce XY sex reversal at embryonic stages. Finally, the knockdown [Smith et al., 2009] or the knockout [Ioannidis et al., 2021] of DMRT1 in early chicken embryos, respectively, induces partial and complete male-to-female gonadal sex reversal. This shows that the avian testicular-determining mechanism is based on DMRT1 dosage.

\section{Transcription Factors Involved in Female Sex Determination}

The search of the genes involved in female sex determination was more challenging, and only few XX DSD 
syndromes with potential loss of function have been genetically characterized in humans.

NROB 1 (originally described as DAX1) is located on the $\mathrm{X}$ chromosome and encodes for an unusual member of nuclear receptor family. NROB1 was first described as an anti-testis gene, because its duplication in human induces dosage sensitive-sensitive XY DSD [Swain et al., 1996] also observed in the mouse [Swain et al., 1998]. However knockout experiments in mouse showed that it is also required for testis determination [Meeks et al., 2003] and its role in ovarian sex determination remains unclear.

Genetic studies in domestic animals harboring DSD of the "male XX" type allowed the identification of FOXL2 as an important player in ovarian development. A rearrangement in chromosome 1q43 that leads to FOXL2 loss of expression in the goat ovary induces a strong masculinization of ovaries with an intersexual phenotype [Pailhoux et al., 2001]. Similarly, FOXL2 loss of function induces testis formation in goat XX fetuses [Boulanger et al., 2014]. In mice, Foxl2 knockout induces sex reversal only after birth [Schmidt et al., 2004; Uhlenhaut et al., 2009], showing again that mice can be different from other mammals. In humans, a link between FOXL2 and ovarian development was initially identified in women with blepharophimosis, ptosis, and epicanthus inversus syndrome type 1 in which FOXL2 heterozygous mutations induce primary ovarian failure [Crisponi et al., 2001].

Moreover, the identification of all mutations/deletions/duplications of genes encoding signaling molecules of the WNT/ $\beta$-catenin pathway in patients with DSD allowed highlighting the crucial role of this pathway in ovarian development, thus adding an important piece to the puzzle of female sex determination. However, the first data came from mice in which Wnt 4 knockout led to masculinization of female pups at birth [Vainio et al., 1999]. Then, it was reported that a duplication of the WNT4 gene caused an XY DSD [Jordan et al., 2003] and that a WNT4 mutation induced virilization in a $46, \mathrm{XX}$ woman [Biason-Lauber et al., 2004], establishing this pathway as the ovarian-determining pathway.

The gene at the top of this cascade was identified in 2006 in a study showing that mutations in RSPO1, which participates in WNT signaling, induce an extremely rare recessive syndrome characterized by XX DSD [Parma et al., 2006]. Later, mouse genetic experiments demonstrated that activation of the $ß$-catenin signaling pathway by RSPO1 is required for ovary development [Chassot et al., 2008; Maatouk et al., 2008]. All these discoveries allowed proposing the concept of the antagonism between FGF9 and WNT4 in embryonic gonads [Kim et al., 2006]. A recent study showing that a mutation in ZNRF3, the antagonist of the WNT pathway, induces XY DSD confirmed that WNT signaling must be repressed in male embryonic gonads to allow testis differentiation [Harris et al., 2018].

However, DSD-causing mutations have not yet been detected in the genes encoding TFs of the TCF/LEF family (i.e., the WNT pathway effectors), probably because germinal mutations in these ubiquitous factors are embryonically lethal. Therefore, little is known about the genomic regions regulated by the WNT pathway in the female gonad.

A recent study has also highlighted RUNX1 as an important actor of the ovarian pathway in vertebrates [Nicol et al., 2019], but up to now, no mutation of this gene has been observed in DSD-patients.

\section{In Search of Target Genes of Sex-Determining Transcription Factors}

Biochemical data on mutated proteins in patients with DSD provide insights into the physiological functions of sex-determining TFs when they interact with their genomic targets. However, this knowledge is only partial and sometimes limited due to conclusions made from in vitro studies. Therefore, it is important to identify, at the genomic level, the target genes of these TFs to better understand their mode of action. For this, chromatin immunoprecipitation (ChIP) is still the technique of choice. Initially, the immuno-purified DNA fragments were used as probes to hybridize microarrays that covered approximately the whole genome of the organism under study ("ChIP-on-Chip" approaches). With the development of next-generation sequencing techniques, "ChIP-on-Chip" has been completely replaced by ChIP-seq approaches where all genomic DNA fragments interacting with the factor of interest are sequenced. Nevertheless, ChIP-seq has several pitfalls:

(i) The quality of the obtained data depends largely on the antibody used for the ChIP step that must be extremely specific.

(ii) It requires a large amount of biological material; therefore, many embryos must be dissected because in vertebrates, embryonic gonads are relatively small. However, it is now possible to perform ChIP-seq with only few million cells.

(iii) As the embryonic gonad is a complex organ composed of several cell populations, only TFs expressed 
in one single cell type can be analyzed by ChIP-seq when using the whole organ (e.g., NR5A1/SF1 i.e. expressed in Sertoli and Leydig cells cannot be investigated).

(iv) As ChIP-seq is limited by the antibody affinity, it cannot be used for single-cell analysis yet.

Therefore, ChIP-seq is in the process of being replaced by the "CUT \& RUN" sequencing approach (i.e., cleavage under targets and release using nuclease) [Skene and Henikoff, 2017] that we will not describe here. As this method requires significantly fewer cells, it could be used to analyze dissociated and purified cells.

One of the problems of genome-wide TF binding profiling is that these experiments often identify thousands of binding sites in the genome, the functional importance of which is sometimes difficult to interpret. Therefore, it is important to combine genomic and transcriptomic approaches. This allows correlating the presence of a TF near a gene with transcription variations of that gene in the presence or absence of that TF.

\section{Genomic Targets of Transcription Factors Controlling the Testicular Pathway}

\section{Genomic Targets of SRY}

SRY is the first known member of the SOX family. It is thought that $S R Y$ was derived from the SOX3 gene located on the X chromosome in mammals. Although SOX3 does not seem to have a role in testis development in mammals, its ectopic expression in embryonic gonads is sufficient to mimic SRY action [Sutton et al., 2011]. In vertebrates, there are only few known examples of SOX proteins acting as master sex-determining genes. Besides therian mammals where SRY is almost generalized, only in the fish Oryzias dancena, a SOX gene (Sox3y) on the Y chromosome initiates the male sex determination cascade [Takehana et al., 2014].

In mice, Sox9 is transcriptionally activated at the peak of Sry expression [Morais da Silva et al., 1996]. This suggests that SOX9 is the candidate of choice for the SRYmediated regulation. However, it has been difficult to identify the regulatory regions of Sox9, a gene located in a desert of nearly $2 \mathrm{Mb}$, and much research was needed to isolate the enhancer regions bound by SRY to activate Sox9 transcription [Gonen et al., 2018; and discussed elsewhere in this issue].

Therefore, an obvious question about $S R Y$ is whether it also has other genomic targets. Genetic studies suggested that the primary role of SRY is to activate SOX9 expres- sion in embryonic Sertoli cell progenitors [Qin and Bishop, 2005]. Indeed, in mice harboring a Y chromosome without the Sry gene and in which Sox9 is constitutively expressed in embryonic gonads, $\mathrm{XY}$ males are fertile. This demonstrates that Sry absence does not prevent the formation of a functional testis as long as Sox9 is expressed and the $\mathrm{Y}$ genes required for spermatogenesis are present.

However, Sox 9 transcriptional activation may require some additional factors that could also be SRY targets. Alternatively, SRY could repress some ovarian genes required for the full activation of Sox9 transcription. In agreement, it has been shown that in vitro, SRY interacts through the KRAB-O protein [Peng et al., 2009] with the transcriptional repressor KAP1, also known as TRIM28, to repress ovarian genes. Moreover, in vitro, SRY represses ß-catenin signaling [Lau and Li, 2009]. Therefore, it will be important to identify SRY targets in mammalian genomes to better understand unexplained XY DSD cases.

A study on SRY and SOX9 target genes using a ChIPon-Chip approach identified many common targets at promoter regions [Li et al., 2014]. Specifically, SRY binds to a fairly large number of promoter regions $(3,083$ peaks or 2,999 different genes). Among these 2,999 genes, 71 are overexpressed in the mouse male supporting cell progenitors that express Sry at E1 1.5 (the time of sex determination in the mouse). These genes might be activated by SRY and represent $14 \%$ of all genes overexpressed in these cells at this stage [Jameson et al., 2012]. Moreover, 56 genes, the promoter region of which is bound by SRY, are more expressed in female pre-granulosa cells at E11.5 [Jameson et al., 2012] and might be repressed by SRY. They represent $15 \%$ of the genes repressed in male gonads. In the list of genes potentially activated by SRY there are genes with a role in male sex determination and which are expressed in Sertoli cells, such as FgF9, Ptgds, Cyp26b1, and Sox8. Among the genes potentially repressed by SRY there are genes expressed in ovaries, such as Bmp2, Fst, and Wnt5a. However, in a large number $(2,872)$ of SRY-bound genes, the transcriptional regulation appears to be similar between sexes. Several hypotheses could explain this. These studies are not based on single-cell analyses, and therefore, the fine transcriptional tuning may be masked by the "bulk" aspect of these approaches. Single-cell transcriptome analyses are now widely used, and the "CUT \& RUN" technique has been adapted to single cells for TF analysis [Hainer et al., 2019]. Therefore, these techniques could soon be exploited to thoroughly study the embryonic gonad differentiation mechanisms. Another hypothesis is that SRY has only a 

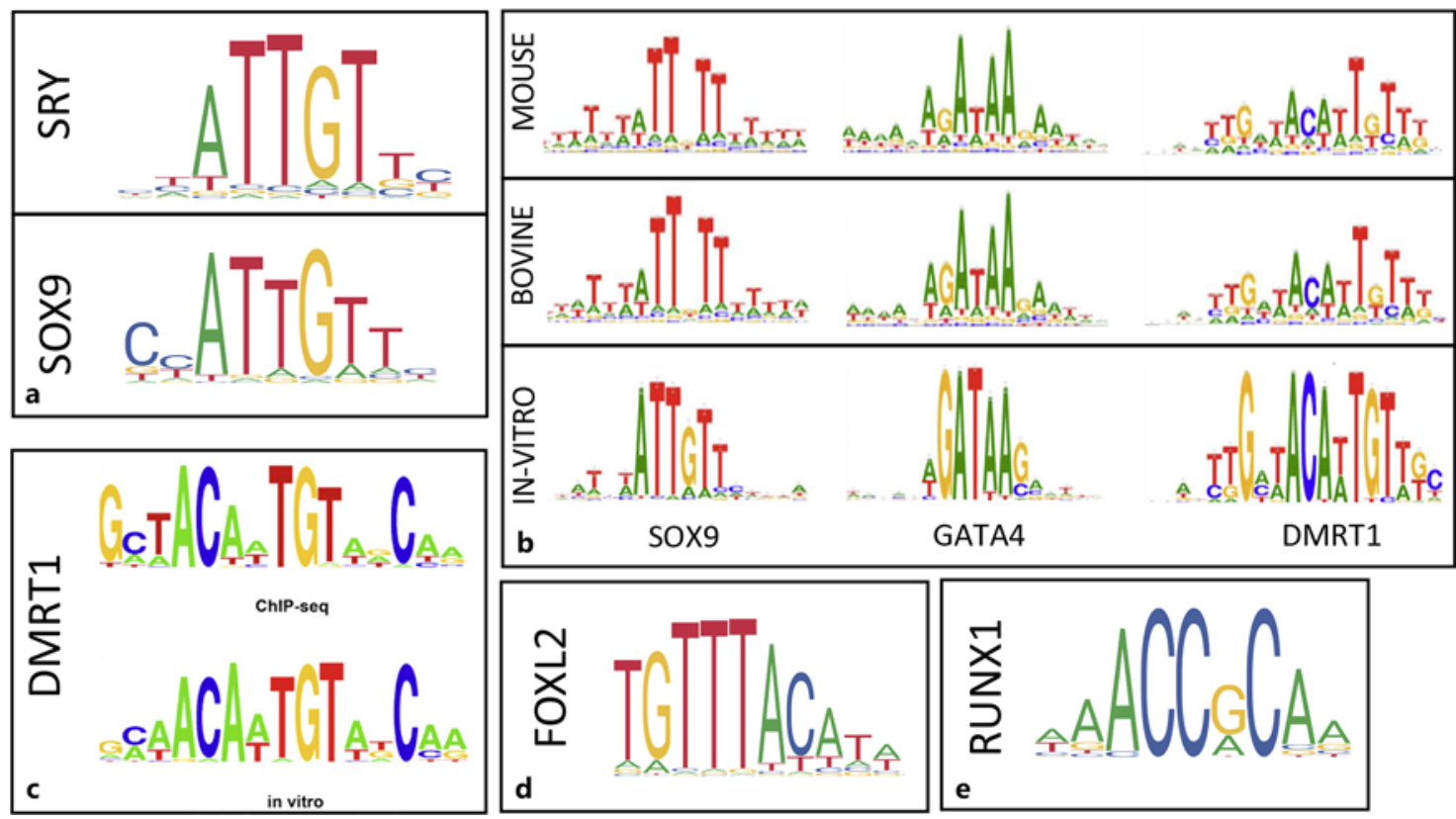

Fig. 1. Examples of DNA-binding motifs of transcription factors involved in mammalian sex determination. a Similarity of motifs recognized by the SRY and SOX9 proteins [Harley et al., 1994; Mertin et al., 1999]. b Compilation of SOX9/GATA4 and DMRT1 motifs characterizing the SCS observed in murine and bovine SOX9 ChIPseq from fetal testes [Rahmoun et al., 2017]. c Compilation of DMRT1 motifs found in DMRT1 ChIP-seq compared to the motif bound by DMRT1 in vitro [adapted from Krentz et al., 2013]. d, e FOXL2 and RUNX1 motifs found in their respective ChIP-seqs performed with mouse fetal ovaries [Nicol et al., 2018,2019]. Logos for motifs in $\mathbf{a}$, in vitro lane in $\mathbf{b}, \mathbf{d}$, and $\mathbf{e}$ were obtained from JASPAR database (http://jaspar.genereg.net).

small number of physiological targets. However, as the motif recognized by its HMG domain [Harley et al., 1994] is relatively loose and frequently present in promoter regions, SRY could bind to many genes without modifying their expression in the absence of other specific partners, such as NR5A1 [Sekido and Lovell-Badge, 2008]. Interestingly this study showed that SRY binds to a large number of regions shared with SOX9 (both have similar DNAbinding motifs) [Harley et al., 1994; Mertin et al., 1999] (Fig. 1a): SRY and SOX9 have 3,083 and 1,903 targets, respectively, among which 907 regions are shared. Then, in vitro luciferase assays showed that in the presence of NR5A1, both TFs can activate the promoter of typical male genes, such as Dhh and Fgf9. However, as SOX9 can activate the testicular pathway on its own [Qin and Bishop, 2005], the SRY-dependent activation of SOX9 targets might be a side effect of the role of SRY at the top of the mammalian cascade.

In conclusion, SRY mode of action has not been fully understood yet. Moreover, the SRY gene is expressed for a transient period in mice (between E10.5 and E12.5) and bovines [Ross et al., 2009]. Conversely, in other mam- mals, such as rabbits [Daniel-Carlier et al., 2013], goats [Montazer-Torbati et al., 2010], and humans Mamsen et al. [2017], it shows an early peak and then remains expressed during fetal life until after birth. Its function after male sex determination and possibly in other tissues apart from the gonad is yet unknown.

\section{Genomic Targets of SOX9}

SOX9 expression in Sertoli cells is a common feature in vertebrates. In mammals, SOX9 expression is crucial for Sertoli cell differentiation. In mice, Sox9 is directly activated by SRY (see above), and its transcriptional activation begins with the peak of Sry expression. SOX9 has been relatively well studied by ChIP-seq in human tissues/cells and in different cancer types: chondrocytes [Ohba et al., 2015; Liu and Lefebvre, 2015], hair follicles [Kadaja et al., 2014], basal cell carcinoma [Larsimont et al., 2015], heart valve [Garside et al., 2015], colorectal cancer [Garside et al., 2015], and pancreatic cancer [Edelman et al., 2021]. In the embryonic gonad, 3 binding site mapping studies were carried out in E12.5 mice (with SRY; see above) [Li et al., 2014], in mouse (E13.5) and bovine fetal 
testes [Rahmoun et al., 2017], and in mouse (E13.5) and chicken male gonads [Yamashita et al., 2019].

Our study carried out in fetal murine and bovine testes [Rahmoun et al., 2017] found that 4,293 SOX9-binding regions are conserved in these 2 mammals (approximately 3,849 genes). This suggests that SOX9 binds to and regulates a similar set of genes in 2 fairly distant mammals. SOX9 peak localization also was similar: $70 \%$ in the gene body, particularly in introns ( $35 \%)$, and $30 \%$ outside the gene, possibly in enhancer-like regions. By combining the ChIP-seq and the transcriptome data for the male and female supporting cells at E13.5, we observed that in male supporting cells, SOX9 binds to 557 activated and 539 repressed genes. In fact, in mouse and bovine fetal gonads, SOX9 seems to bind to virtually all genes known to play a role in sex determination. However, there is still a large number of genes $(4,748$ of 5,844 genes in mice) that are bound by SOX9 but that do not show any transcription level difference between male and female gonads. Moreover, comparison of the transcriptomes of mouse male, female, and XY gonads in which the Sox9 gene was deleted $\left(\operatorname{Sox} 9^{\Delta / \Delta}\right.$ ) indicated that SOX9 binds to genes (particularly in junction regions between introns and exons) the splicing of which is modified in Sox $9^{\Delta / \Delta}$ gonads [Rahmoun et al., 2017]. The splicing changes induced by Sox 9 loss affect all forms of alternative splicing, including intron retention, leading to significant modifications of the resulting proteins. An in vitro study showed that SOX9 modulates splicing independently of its TF activity [Girardot et al., 2018], probably by binding directly to RNA and interacting with RNA-binding proteins, such as p54nrb/NONO, Sam68, and Y14/RBM8A that belong to the exon junction complex [Le Hir et al., 2016] involved in alternative splicing in Drosophila [Ashton-Beaucage et al., 2010]. Therefore, it could be hypothesized that SOX9 regulates splicing of its target genes without affecting their transcription through 2 separate mechanisms: binding to chromatin and direct binding to RNA. More experiments are needed to verify this hypothesis in vivo.

In the mouse, SOX9 on its own can induce testis differentiation when expressed ectopically in the XX gonad [Vidal et al., 2001]. Its target regions in the Sertoli cell genome might contain the binding motifs for the key TFs involved in testis differentiation. Consequently these TFs might bind together with SOX9, especially the 4 TFs that with SOX9 can reprogram fibroblasts into embryonic Sertoli like-cells (NR5A1, GATA4, DMRT1, WT1) [Buganim et al., 2012].

The genomic regions bound by SOX9 in murine and bovine fetal testes show an enrichment for the SOX9,
GATA4, and DMRT1 motifs (Fig. 1b) with a precise stoichiometry that is conserved among orthologous sequences of eutherian mammals. This motif grouping, which we called the Sertoli cells signature (SCS), does not come from repeated sequences and therefore, was not brought into the genome by successive transposon invasions of vertebrate genomes. It should be noted that the SCS includes the motifs recognized by SOX9 and DMRT1, 2 of the major TFs implicated in the testicular program in vertebrates. Moreover, our unpublished results show that the SCS is also present in the chicken and fish genomes. The presence of the GATA4 motif in SCS can be explained by the fact that this TF is necessary for genital crest formation in the mouse [Hu et al., 2013]. Moreover, GATA4 has been described as a pioneer factor [Gualdi et al., 1996] required with FOXA for hepatic endodermal induction [Lee et al., 2005]. Therefore, GATA4 could facilitate the access to the cis regulatory element of the genes that define the somatic gonad program. Noteworthy, a recent study in adult mice found that DMRT1 also is a pioneer factor for SOX9 [Lindeman et al., 2021]. However, it is not known how this particular DNA motif enrichment that composes the SCS was constituted.

\section{Genomic Targets of DMRT1}

DM-domain TFs are found throughout the animal kingdom, and DMRT1 is associated with male sex determination in vertebrate and invertebrates ( $\mathrm{Dxl}$ in D. melanogaster and mab-3 in C. elegans). Unlike SOX9, DMRT1 is also involved in germline maturation in mammals, and this complicates the ChIP-seq study of its target genes in Sertoli cells. DMRT1 genomic binding profile has only been investigated in mammals, and it is not known whether it is conserved in other vertebrates. In E13.5 mouse fetal testes, DMRT1 binds to 2,430 genomic regions, representing 2,137 annotated genes [Krentz et al., 2013]. As described for SOX9, peaks are mainly located in gene bodies ( $48.6 \%$ of which $39 \%$ are in introns), followed by upstream (37\%) and downstream intergenic regions (14\%). Interestingly, 570 regions are shared by SOX9 and DMRT1, and they also present an enrichment for the SOX/DMRT/GATA binding motifs, as observed in regions bound by SOX9. ChIP-re-ChIP experiments, also known as sequential chromatin immunoprecipitation [Beischlag et al., 2018], confirmed that these regions are bound by both TFs [Rahmoun et al., 2017]. Among the TFs involved in testis differentiation, DMRT1 recognizes the longest motif. Indeed, DMRT1 binds in vitro to a 13-bp pseudo-palindromic motif [Murphy et al., 2007] that is very similar to the motifs found in the peaks of 
DMRT1 ChIP-seq [Krentz et al., 2013] (Fig. 1c). Interestingly, ChIP-exo experiments (ChIP followed by exonuclease digestion) showed that in vivo DMRT1 binds to DNA as a dimer, trimer, or tetramer, depending on the organization of the target DNA sequence [Murphy et al., 2015].

The role of DMRT1 does not seem to be the same in all mammalian species, because deletions [Veitia et al., 1997] or mutations [Murphy et al., 2015] in humans induce XY DSD, while in mice Dmrt1 ablation does not cause sex reversal but only severe reduction of the testis size and lack of germ cells [Raymond et al., 2000]. Nevertheless, DMRT1 is required to maintain the identity of adult Sertoli cells, because in its absence they will transdifferentiate into pseudo-granulosa cells [Matson et al., 2011]. Likewise, ectopic expression of DMRT1 in granulosa cells induces their postnatal transdifferentiation into Sertoli cells [Lindeman et al., 2015] that express Sox9 and Sox8. Using this mouse model, David Zarkower's group showed that DMRT1 plays a pioneering role in recruiting SOX9 to regulatory elements to activate their targets genes. In the absence of DMRT1, SOX9 capacity to activate the testis program is significantly reduced [Lindeman et al., 2021]. It is not known whether this mechanism is active also in the embryonic gonad because Dmrt1 knockout does not induce sexreversal [Raymond et al., 2000]. However, other DMRT family members are expressed in the embryonic gonad somatic cells, such as Dmrt1a1 and $1 b$ [Jameson et al., 2012], and they could compensate the absence of DMRT1. In agreement, in humans, XY DSD linked to $D M R T 1$ are essentially caused by deletions of large regions of chromosome 9p24.1 [Veitia et al., 1997] that include also other proximal DMRT genes (DMRT2 and 3). Interestingly, DMRT1 has a masculinizing effect in XX embryonic gonads only if the transgene is strongly expressed [Zhao et al., 2015]. If expressed at the physiological level observed in XY gonads, sex reversal occurs only after birth [Lindeman et al., 2015].

\section{Genomic Targets of Transcription Factors Controlling the Ovarian Pathway}

In the female embryonic gonad, ovarian differentiation is regulated by the RSPO1/WNT4 and FOXL2 pathways. The canonical WNT pathway involves TFs of the TCF/LEF family. However, these factors (e.g., LEF1) are expressed in somatic and also germ cells of the fetal ovary, and it is difficult to analyze them by ChIP-seq without physically separating the 2 populations.

Transcription Factor and Sex

Determination

\section{Genomic Targets of FOXL2}

This TF is specifically expressed in ovarian somatic cells, and its binding to target genes has been analyzed in embryonic [Nicol et al., 2018] and postnatal ovaries [Georges et al., 2014]. In the embryonic ovary, FOXL2 binds to 11,438 regions, corresponding to 9,324 genes. Most FOXL2 peaks are located in the gene body (promoter: $25 \%$; exons: $26 \%$; introns: $24 \%$ ) and $25 \%$ of peaks are in distant non-coding regions. Combining these data on genes bound by FOXL2 with transcriptome analyses of Foxl2 knockout ovaries [Garcia-Ortiz et al., 2009] and fetal Sertoli cells [Jameson et al., 2012] showed that FOXL2 actively promotes the activity of genes in granulosa cells, while repressing some of the genes expressed in Sertoli cells. This finding is in good agreement with the Foxl2 knockout data in adult ovaries where the granulosa program is turned off concomitantly with the activation of the adult Sertoli program.

Similarly, 35\% of the peaks bound by FOXL2 in E13.5 ovaries overlaps with those bound by SOX9 in E13.5 testes and $5 \%$ with those bound by DMRT1. Therefore, there is a significant overlap in chromatin occupation by FOXL2 and SOX9, showing that the antagonism between the testicular and ovarian pathways can be also found at the chromatin level.

Some typical ovarian genes are activated by FOXL2 (e.g., Fst, Bmp2, and $C d k n 1 b$ ), while testicular genes (e.g., Dmrt1, Cyp26b1, and Fgf9) are repressed. Concerning gene organization in topological domains, and in accordance with the TAD (topologically associating domains) model where chromatin is separated into active and repressed compartments, a recent study, although in adults, reported that a majority of TADs in which genes were regulated by FOXL2 were in the same direction (i.e., all downregulated or upregulated) [Herman et al., 2021].

\section{Genomic Targets of RUNX1}

A recent study [Nicol et al., 2019] showed that RUNX1, a RUNX family member, is expressed in vertebrate ovaries, from fish to primates, and may have an important role in female sex determination. In the mouse, RUNX1 is expressed in undetermined supporting cells and then is specifically detected in pre-granulosa cells as the ovary differentiates. Importantly, the combined deletion of Runx 1 and Foxl2 induces a stronger masculinization of the ovarian transcriptome than each single knockout, suggesting that they have a complementary role in maintaining the granulosa cell identity. Double mutant ovaries display a testis-like structure with testis cords that express DMRT1, but masculinization is not complete because 
SOX9 is not expressed [Nicol et al., 2019]. Genome-wide, there is a significantly overlap $(5,619 ; 54 \%)$ between regions occupied by FOXL2 $(11,438)$ [Nicol et al., 2018] and RUNX1 $(10,494)$ in fetal ovaries, indicating that these 2 TFs occupy common target regions. Concerning the DNA motifs recognized by these proteins, besides the FOXL2 motif (Fig. 1d), there is also a clear enrichment of FOXL2. This strengthens the model according to which the granulosa cell fate. At the transcriptional level, only 197 genes bound by both TFs display a clear transcription variation in the double mutant. This difference between the important number of genes bound by the 2 TFs and ble mutant questions again the physiological relevance of the thousand binding peaks observed in ChIP-seq analyses.

\section{Concluding Remarks}

The study of the interaction between TFs and the noncoding regions that they bind to regulate the transcription of proximal genes has been incredibly accelerated in the past 20 years. The advances in sequencing techniques asnome-wide manner. However, many aspects remain obscure concerning these crucial proteins during gonad development. For example, it is difficult to determine whether 2 TFs cohabit on the same genomic region in a single cell and to appreciate their effect on the transcriptional regulation of the proximal genes. As hypothesized before in this manuscript, TF function in gene regulation can be only poorly analyzed with bulk approaches that combine ChIP-seq and RNA-seq. Single-cell studies are required to decipher the crosstalk among TFs binding to their target sequence and the fine regulation of neighboring genes.

With regard to sex determination, a global view is now available concerning the function of some of the major sex-determining TFs (reviewed here); however, the role of other crucial factors, such as NR5A1, WT1, GATA4, and LEF/TCF, at the genomic level remains unknown in both male and female gonads and needs to be determined. Moreover, the genomic profiling of the major sex-determining TFs in different vertebrate species would bring insights into the conservation of the genetic program regulated by these proteins during evolution. Such study would also provide information on the conservation of RUNX1 motifs (Fig. 1e) within the regions bound by FOXL2 and RUNX1 collaborate on chromatin to control the relatively small number of genes affected in the dousociated with ChIP allow studying the TF action in a ge-

the DNA motifs that define the genomic grammar underpinning a particular cell fate. The analysis of TF binding motifs allowed deciphering, at least partially, the genomic signature that characterizes regions bound by SOX9 in Sertoli cells. The emergence of RUNX1 as an important FOXL2 co-factor in the female pathway might allow determining whether a granulosa cell signature also exists in mammalian genomes.

\section{Acknowledgments}

Thanks to Elisabetta Andermarcher for manuscript editing.

\section{Conflict of Interest Statement}

The author has no conflicts of interest to declare.

\section{Funding Sources}

This work was supported by the Centre National de la Recherche Scientifique (CNRS), the University of Montpellier, and by a grant from "Agence Nationale de la Recherche" (ANR-16- 20 CE14-0020-SexMaintain to F.P).

\section{Author Contributions}

F.P. wrote the manuscript.
References
Achermann JC, Ito M, Ito M, Hindmarsh PC, Jameson JL. A mutation in the gene encoding steroidogenic factor- 1 causes XY sex reversal and adrenal failure in humans. Nat Genet. 1999;22:125-6

Andersson R, Sandelin A. Determinants of enhancer and promoter activities of regulatory elements. Nat Rev Genet. 2020;21:71-87.

Argentaro A, Sim H, Kelly S, Preiss S, Clayton A, Jans DA, et al. A SOX9 defect of calmodulindependent nuclear import in campomelic dysplasia/autosomal sex reversal. J Biol Chem. 2003;278:33839-47.

Ashton-Beaucage D, Udell CM, Lavoie H, Baril C, Lefrançois $\mathrm{M}$, Chagnon $\mathrm{P}$, et al. The exon junction complex controls the splicing of MAPK and other long intron-containing transcripts in Drosophila. Cell. 2010;143: 251-62.

Barbaux S, Niaudet P, Gubler MC, Grünfeld JP, Jaubert F, Kuttenn F, et al. Donor splice-site mutations in WT1 are responsible for Frasier syndrome. Nat Genet. 1997;17:467-70. 
Barrionuevo FJ, Hurtado A, Kim GJ, Real FM, Bakkali M, Kopp JL, et al. Sox9 and Sox8 protect the adult testis from male-to-female genetic reprogramming and complete degeneration. eLife. 2016;5:e15635.

Bashamboo A, Donohoue PA, Vilain E, Rojo S, Calvel P, Seneviratne SN, et al. A recurrent p.Arg92Trp variant in steroidogenic factor-1 (NR5A1) can act as a molecular switch in human sex development. Hum Mol Genet. 2016; 25:3446-53.

Beischlag TV, Prefontaine GG, Hankinson O. ChIP-re-ChIP: Co-occupancy analysis by sequential chromatin immunoprecipitation. Methods Mol Biol. 2018;1689:103-12.

Berta P, Hawkins JR, Sinclair AH, Taylor A, Griffiths BL, Goodfellow PN, et al. Genetic evidence equating SRY and the testis-determining factor. Nature. 1990;348:448-50.

Biason-Lauber A, Konrad D, Navratil F, Schoenle EJ. A WNT4 mutation associated with Müllerian-duct regression and virilization in a 46,XX woman. N Engl J Med. 2004;351:7928.

Boulanger L, Pannetier M, Gall L, Allais-Bonnet A, Elzaiat M, Le Bourhis D, et al. FOXL2 is a female sex-determining gene in the goat. Curr Biol. 2014;24:404-8.

Buganim Y, Itskovich E, Hu YC, Cheng AW, Ganz K, Sarkar S, et al. Direct reprogramming of fibroblasts into embryonic sertoli-LIKE cells by defined factors. Cell Stem Cell. 2012; 11:373-86.

Capel B. Vertebrate sex determination: evolutionary plasticity of a fundamental switch. Nat Rev Genet. 2017;18:675-89.

Chassot AA, Ranc F, Gregoire EP, Roepers-Gajadien HL, Taketo MM, Camerino G, et al. Activation of beta-catenin signaling by Rspo 1 controls differentiation of the mammalian ovary. Hum Mol Genet. 2008;17:1264-77.

Crisponi L, Deiana M, Loi A, Chiappe F, Uda M, Amati $\mathrm{P}$, et al. The putative forkhead transcription factor FOXL2 is mutated in blepharophimosis/ptosis/epicanthus inversus syndrome. Nat Genet. 2001;27:159-66.

Czerwinski M, Natarajan A, Barske L, Looger LL, Capel B. A timecourse analysis of systemic and gonadal effects of temperature on sexual development of the red-eared slider turtle Trachemys scripta elegans. Dev Biol. 2016; 420:166-77.

Daniel-Carlier N, Harscoët E, Thépot D, Auguste A, Pailhoux E, Jolivet G. Gonad differentiation in the rabbit: evidence of species-specific features. PLoS One. 2013;8:e60451.

Edelman HE, McClymont SA, Tucker TR, Pineda S, Beer RL, McCallion AS, et al. SOX9 modulates cancer biomarker and cilia genes in pancreatic cancer. Hum Mol Genet. 2021;30(6): 485-99.

Eozenou C, Gonen N, Touzon MS, Jorgensen A, Yatsenko SA, Fusee L, et al. Testis formation in XX individuals resulting from novel pathogenic variants in Wilms' tumor 1 (WT1) gene. Proc Natl Acad Sci U S A. 2020;117(24): 13680-8.
Foster JW, Dominguez-Steglich MA, Guioli S, Kwok C, Weller PA, Stevanović M, et al. Campomelic dysplasia and autosomal sex reversal caused by mutations in an SRY-related gene. Nature. 1994;372:525-30.

Garcia-Ortiz JE, Pelosi E, Omari S, Nedorezov T, Piao Y, Karmazin J, et al. Foxl2 functions in sex determination and histogenesis throughout mouse ovary development. BMC Dev Biol. 2009;9:36.

Garcia-Perez JL, Widmann TJ, Adams IR. The impact of transposable elements on mammalian development. Development. 2016;143: 4101-14.

Garside VC, Cullum R, Alder O, Lu DY, Vander Werff R, Bilenky M, et al. SOX9 modulates the expression of key transcription factors required for heart valve development. Development. 2015;142:4340-50

Ge C, Ye J, Weber C, Sun W, Zhang H, Zhou Y, et al. The histone demethylase KDM6B regulates temperature-dependent sex determination in a turtle species. Science. 2018;360:6458.

Ge C, Ye J, Zhang H, Zhang Y, Sun W, Sang Y, et al. Dmrt1 induces the male pathway in a turtle species with temperature-dependent sex determination. Development. 2017;144:222233.

Georges A, L'Hôte D, Todeschini AL, Auguste A, Legois B, Zider A, et al. The transcription factor FOXL2 mobilizes estrogen signaling to maintain the identity of ovarian granulosa cells. eLife. 2014;3:e04207.

Girardot M, Bayet E, Maurin J, Fort P, Roux P, Raynaud P. SOX9 has distinct regulatory roles in alternative splicing and transcription. Nucleic Acids Res. 2018;46:9106-18.

Gonen N, Futtner CR, Wood S, Garcia-Moreno SA, Salamone IM, Samson SC, et al. Sex reversal following deletion of a single distal enhancer of Sox9. Science. 2018;360:1469-73.

Gualdi R, Bossard P, Zheng M, Hamada Y, Coleman JR, Zaret KS. Hepatic specification of the gut endoderm in vitro: cell signaling and transcriptional control. Genes Dev. 1996;10: 1670-82.

Gubbay J, Collignon J, Koopman P, Capel B, Economou A, Münsterberg A, et al. A gene mapping to the sex-determining region of the mouse Y chromosome is a member of a novel family of embryonically expressed genes. $\mathrm{Na}-$ ture. 1990;346:245-50.

Hainer SJ, Bošković A, McCannell KN, Rando OJ, Fazzio TG. Profiling of pluripotency factors in single cells and early embryos. Cell. 2019; 177:1319-e11.

Harley VR, Jackson DI, Hextall PJ, Hawkins JR, Berkovitz GD, Sockanathan S, et al. DNA binding activity of recombinant SRY from normal males and XY females. Science. 1992; 255:453-6.

Harley VR, Lovell-Badge R, Goodfellow PN. Definition of a consensus DNA binding site for SRY. Nucleic Acids Res. 1994;22:1500-1.
Harris A, Siggers P, Corrochano S, Warr N, Sagar $\mathrm{D}$, Grimes DT, et al. ZNRF3 functions in mammalian sex determination by inhibiting canonical WNT signaling. Proc Natl Acad Sci U S A. 2018;115:5474-9.

Herman L, Legois B, Todeschini AL, Veitia RA. Genomic exploration of the targets of FOXL2 and ESR2 unveils their implication in cell migration, invasion, and adhesion. FASEB J. 2021;35(4):e21355.

Herpin A, Braasch I, Kraeussling M, Schmidt C, Thoma EC, Nakamura S, et al. Transcriptional rewiring of the sex determining dmrtl gene duplicate by transposable elements. PLoS Genet. 2010;6:e1000844.

Hirst CE, Major AT, Smith CA. Sex determination and gonadal sex differentiation in the chicken model. Int J Dev Biol. 2018;62:15366.

Holleley CE, O'Meally D, Sarre SD, Marshall Graves JA, Ezaz T, Matsubara K, et al. Sex reversal triggers the rapid transition from genetic to temperature-dependent sex. Nature. 2015;523:79-82.

Houston CS, Opitz JM, Spranger JW, Macpherson RI, Reed MH, Gilbert EF, et al. The campomelic syndrome: review, report of 17 cases, and follow-up on the currently 17 -year-old boy first reported by Maroteaux et al in 1971 . Am J Med Genet. 1983;15:3-28.

Hu YC, Okumura LM, Page DC. Gata4 is required for formation of the genital ridge in mice. PLoS Genet. 2013;9:e1003629.

Huang B, Wang S, Ning Y, Lamb AN, Bartley J. Autosomal XX sex reversal caused by duplication of SOX9. Am J Med Genet. 1999;87:349-53.

Ioannidis J, Taylor G, Zhao D, Liu L, Idoko-Akoh A, Gong D, et al. Primary sex determination in birds depends on DMRT1 dosage, but gonadal sex does not determine adult secondary sex characteristics. Proc Natl Acad Sci U S A. 2021;118(10):e2020909118.

Jameson SA, Natarajan A, Cool J, DeFalco T, Maatouk DM, Mork L, et al. Temporal transcriptional profiling of somatic and germ cells reveals biased lineage priming of sexual fate in the fetal mouse gonad. PLoS Genet. 2012;8: e1002575.

Jordan BK, Shen JH, Olaso R, Ingraham HA, Vilain E. Wnt4 overexpression disrupts normal testicular vasculature and inhibits testosterone synthesis by repressing steroidogenic factor 1/beta-catenin synergy. Proc Natl Acad Sci U S A. 2003;100:10866-71.

Kadaja M, Keyes BE, Lin M, Pasolli HA, Genander M, Polak L, et al. SOX9: a stem cell transcriptional regulator of secreted niche signaling factors. Genes Dev. 2014;28:328-41.

Kim Y, Capel B. Balancing the bipotential gonad between alternative organ fates: A new perspective on an old problem. Dev Dyn. 2006; 235:2292-300.

Kim Y, Kobayashi A, Sekido R, DiNapoli L, Brennan J, Chaboissier MC, et al. Fgf9 and Wnt4 act as antagonistic signals to regulate mammalian sex determination. PLoS Biol. 2006;4: e187. 
Klemm SL, Shipony Z, Greenleaf WJ. Chromatin accessibility and the regulatory epigenome. Nat Rev Genet. 2019;20:207-20.

Knower KC, Kelly S, Harley VR. Turning on the male--SRY, SOX9 and sex determination in mammals. Cytogenet Genome Res. 2003;101: 185-98.

Koopman P, Gubbay J, Vivian N, Goodfellow P, Lovell-Badge R. Male development of chromosomally female mice transgenic for Sry. Nature. 1991;351:117-21.

Krentz AD, Murphy MW, Zhang T, Sarver AL, Jain $\mathrm{S}$, Griswold $\mathrm{MD}$, et al. Interaction between DMRT1 function and genetic background modulates signaling and pluripotency to control tumor susceptibility in the fetal germ line. Dev Biol. 2013;377:67-78.

Kvon EZ, Waymack R, Gad M, Wunderlich Z. Enhancer redundancy in development and disease. Nat Rev Genet. 2021;22(5):324-36.

Larsimont JC, Youssef KK, Sánchez-Danés A, Sukumaran V, Defrance M, Delatte B, et al. Sox 9 controls self-renewal of oncogene targeted cells and links tumor initiation and invasion. Cell Stem Cell. 2015;17:60-73.

Lasala C, Carré-Eusèbe D, Picard JY, Rey R. Subcellular and molecular mechanisms regulating anti-Müllerian hormone gene expression in mammalian and nonmammalian species. DNA Cell Biol. 2004;23:572-85.

Lau YF, Li Y. The human and mouse sex-determining SRY genes repress the Rspol/betacatenin signaling. J Genet Genomics. 2009;36 193-202.

Le Hir H, Saulière J, Wang Z. The exon junction complex as a node of post-transcriptional networks. Nat Rev Mol Cell Biol. 2016;17:41-54.

Lee CS, Friedman JR, Fulmer JT, Kaestner KH. The initiation of liver development is dependent on Foxa transcription factors. Nature. 2005;435:944-7.

Li Y, Zheng M, Lau YF. The sex-determining factors SRY and SOX9 regulate similar target genes and promote testis cord formation during testicular differentiation. Cell Rep. 2014; 8:723-33.

Lindeman RE, Gearhart MD, Minkina A, Krentz $\mathrm{AD}$, Bardwell VJ, Zarkower D. Sexual cell-fate reprogramming in the ovary by DMRT1. Curr Biol. 2015;25:764-71.

Lindeman RE, Murphy MW, Agrimson KS, Gewiss RL, Bardwell VJ, Gearhart MD, et al. The conserved sex regulator DMRT1 recruits SOX9 in sexual cell fate reprogramming. $\mathrm{Nu}-$ cleic Acids Res. 2021;49(11):6144-64.

Liu CF, Lefebvre V. The transcription factors SOX9 and SOX5/SOX6 cooperate genomewide through super-enhancers to drive chondrogenesis. Nucleic Acids Res. 2015;43:8183203.

Maatouk DM, Dinapoli L, Alvers A, Parker KL, Taketo MM, Capel B. Stabilization of betacatenin in XY gonads causes male-to-female sex-reversal. Hum Mol Genet. 2008;17:2949_ 55.
Maatouk DM, Natarajan A, Shibata Y, Song L, Crawford GE, Ohler U, et al. Genome-wide identification of regulatory elements in Sertoli cells. Development. 2017;144:720-30.

Mamsen LS, Ernst EH, Borup R, Larsen A, Olesen $\mathrm{RH}$, Ernst E, et al. Temporal expression pattern of genes during the period of sex differentiation in human embryonic gonads. Sci Rep. 2017;7:15961.

Matson CK, Murphy MW, Sarver AL, Griswold MD, Bardwell VJ, Zarkower D. DMRT1 prevents female reprogramming in the postnatal mammalian testis. Nature. 2011;476:101-4.

McDowall S, Argentaro A, Ranganathan S, Weller $\mathrm{P}$, Mertin S, Mansour S, et al. Functional and structural studies of wild type SOX9 and mutations causing campomelic dysplasia. J Biol Chem. 1999;274:24023-30.

McElreavey K, Achermann JC. Steroidogenic factor-1 (SF-1, NR5A1) and 46,XX ovotesticular disorders of sex development:One factor, many phenotypes. Horm Res Paediatr. 2017; 87:189-90.

Meeks JJ, Weiss J, Jameson JL. Dax1 is required for testis determination. Nat Genet. 2003;34: $32-3$.

Mertin S, McDowall SG, Harley VR. The DNAbinding specificity of SOX9 and other SOX proteins. Nucleic Acids Res. 1999;27:135964.

Montazer-Torbati F, Kocer A, Auguste A, Renault L, Charpigny G, Pailhoux E, et al. A study of goat SRY protein expression suggests putative new roles for this gene in the developing testis of a species with long-lasting SRY expression. Dev Dyn. 2010;239:3324-35.

Morais da Silva S, Hacker A, Harley V, Goodfellow P, Swain A, Lovell-Badge R. Sox9 expression during gonadal development implies a conserved role for the gene in testis differentiation in mammals and birds. Nat Genet. 1996; 14:62-8.

Murphy MW, Lee JK, Rojo S, Gearhart MD, Kurahashi K, Banerjee S, et al. An ancient protein-DNA interaction underlying metazoan sex determination. Nat Struct Mol Biol. 2015; 22:442-51.

Murphy MW, Zarkower D, Bardwell VJ. Vertebrate DM domain proteins bind similar DNA sequences and can heterodimerize on DNA. BMC Mol Biol. 2007;8:58.

Nanda I, Shan Z, Schartl M, Burt DW, Koehler M, Nothwang H, et al. 300 million years of conserved synteny between chicken $Z$ and human chromosome 9. Nat Genet. 1999;21:258-9.

Nicol B, Grimm SA, Chalmel F, Lecluze E, Pannetier M, Pailhoux E, et al. RUNX1 maintains the identity of the fetal ovary through an interplay with FOXL2. Nat Commun. 2019;10: 5116.

Nicol B, Grimm SA, Gruzdev A, Scott G, Ray MK, Yao HH. Genome-wide identification of FOXL2 binding and characterization of FOXL2 feminizing action in the fetal gonads. Hum Mol Genet. 2018;27:4273-87.
Ohba S, He X, Hojo H, McMahon AP. Distinct transcriptional programs underlie Sox9 regulation of the mammalian chondrocyte. Cell Rep. 2015;12:229-43.

Pailhoux E, Vigier B, Chaffaux S, Servel N, Taourit $\mathrm{S}$, Furet JP, et al. A 11.7-kb deletion triggers intersexuality and polledness in goats. Nat Genet. 2001;29:453-8.

Pan Q, Kay T, Depince A, Adolfi M, Schartl M, Guiguen Y, et al. Evolution of master sex determiners: TGF-beta signalling pathways at regulatory crossroads. Philos Trans R Soc Lond B Biol Sci. 2021;376:20200091.

Parma P, Radi O, Vidal V, Chaboissier MC, Dellambra E, Valentini S, et al. R-spondin1 is essential in sex determination, skin differentiation and malignancy. Nat Genet. 2006;38: 1304-9.

Pelletier J, Bruening W, Kashtan CE, Mauer SM, Manivel JC, Striegel JE, et al. Germline mutations in the Wilms' tumor suppressor gene are associated with abnormal urogenital development in Denys-Drash syndrome. Cell. 1991; 67:437-47.

Peng H, Ivanov AV, Oh HJ, Lau YF, Rauscher FJ 3rd . Epigenetic gene silencing by the SRY protein is mediated by a KRAB-O protein that recruits the KAP1 co-repressor machinery. J Biol Chem. 2009;284:35670-80.

Platt RN, 2nd, Vandewege MW, Ray DA. Mammalian transposable elements and their impacts on genome evolution. Chromosome Res. 2018;26:25-43.

Polanco JC, Wilhelm D, Davidson TL, Knight D, Koopman P. Sox10 gain-of-function causes $\mathrm{XX}$ sex reversal in mice: implications for human 22q-linked disorders of sex development. Hum Mol Genet. 2010;19:506-16.

Pontiggia A, Rimini R, Harley VR, Goodfellow PN, Lovell-Badge R, Bianchi ME. Sex-reversing mutations affect the architecture of SRYDNA complexes. Embo J. 1994;13:6115-24.

Portnoi MF, Dumargne MC, Rojo S, Witchel SF, Duncan AJ, Eozenou C, et al. Mutations involving the SRY-related gene SOX8 are associated with a spectrum of human reproductive anomalies. Hum Mol Genet. 2018;27: 1228-40.

Qin Y, Bishop CE. Sox9 is sufficient for functional testis development producing fertile male mice in the absence of Sry. Hum Mol Genet. 2005; 14:1221-9.

Rahmoun M, Lavery R, Laurent-Chaballier S, Bellora N, Philip GK, Rossitto M, et al. In mammalian foetal testes, SOX9 regulates expression of its target genes by binding to genomic regions with conserved signatures. Nucleic Acids Res. 2017;45:7191-211.

Raymond CS, Shamu CE, Shen MM, Seifert KJ, Hirsch B, Hodgkin J, et al. Evidence for evolutionary conservation of sex-determining genes. Nature. 1998;391:691-5.

Raymond CS, Kettlewell JR, Hirsch B, Bardwell VJ, Zarkower D. Expression of Dmrt1 in the genital ridge of mouse and chicken embryos suggests a role in vertebrate sexual development. Dev Biol. 1999;215:208-20. 
Raymond CS, Murphy MW, O'Sullivan MG, Bardwell VJ, Zarkower D. Dmrt1, a gene related to worm and fly sexual regulators, is required for mammalian testis differentiation. Genes Dev. 2000;14:2587-95.

Ross DG, Bowles J, Hope M, Lehnert S, Koopman $P$. Profiles of gonadal gene expression in the developing bovine embryo. Sex Dev. 2009;3: 273-83.

Sartorelli V, Lauberth SM. Enhancer RNAs are an important regulatory layer of the epigenome. Nat Struct Mol Biol. 2020;27:521-8.

Schepers G, Wilson M, Wilhelm D, Koopman P. SOX8 is expressed during testis differentiation in mice and synergizes with SF1 to activate the Amh promoter in vitro. J Biol Chem. 2003;278:28101-8.

Schmidt D, Ovitt CE, Anlag K, Fehsenfeld S, Gredsted L, Treier AC, et al. The murine winged-helix transcription factor Foxl2 is required for granulosa cell differentiation and ovary maintenance. Development. 2004;131: 933-42.

Sekido R, Lovell-Badge R. Sex determination involves synergistic action of SRY and SF1 on a specific Sox9 enhancer. Nature. 2008;453: 930-4.

Sinclair AH, Berta P, Palmer MS, Hawkins JR, Griffiths BL, Smith MJ, et al. A gene from the human sex-determining region encodes a protein with homology to a conserved DNAbinding motif. Nature. 1990;346:240-4.

Skene PJ, Henikoff S. An efficient targeted nuclease strategy for high-resolution mapping of DNA binding sites. Elife. 2017;6:e21856.
Smith CA, Roeszler KN, Ohnesorg T, Cummins DM, Farlie PG, Doran TJ, et al. The avian Zlinked gene DMRT1 is required for male sex determination in the chicken. Nature. 2009; 461:267-71.

Sudbeck P, Schmitz ML, Baeuerle PA, Scherer G. Sex reversal by loss of the C-terminal transactivation domain of human SOX9. Nat Genet. 1996;13:230-2.

Sutton E, Hughes J, White S, Sekido R, Tan J, Arboleda $\mathrm{V}$, et al. Identification of SOX3 as an $\mathrm{XX}$ male sex reversal gene in mice and humans. J Clin Invest. 2011;121:328-41.

Swain A, Zanaria E, Hacker A, Lovell-Badge R, Camerino G. Mouse Dax1 expression is consistent with a role in sex determination as well as in adrenal and hypothalamus function. Nat Genet. 1996;12:404-9.

Swain A, Narvaez V, Burgoyne P, Camerino G, Lovell-Badge R. Daxl antagonizes Sry action in mammalian sex determination. Nature. 1998;391:761-7.

Takehana Y, Matsuda M, Myosho T, Suster ML, Kawakami K, Shin-I T, et al. Co-option of Sox3 as the male-determining factor on the $\mathrm{Y}$ chromosome in the fish Oryzias dancena. Nat Commun. 2014;5:4157.

Uhlenhaut NH, Jakob S, Anlag K, Eisenberger T, Sekido R, Kress J, et al. Somatic sex reprogramming of adult ovaries to testes by FOXL2 ablation. Cell. 2009;139:1130-42.

Vainio S, Heikkilä M, Kispert A, Chin N, McMahon AP. Female development in mammals is regulated by Wnt-4 signalling. Nature. 1999; 397:405-9.
Veitia R, Nunes M, Brauner R, Doco-Fenzy M, Joanny-Flinois O, Jaubert F, et al. Deletions of distal $9 \mathrm{p}$ associated with $46, \mathrm{XY}$ male to female sex reversal: definition of the breakpoints at 9p23.3-p24.1. Genomics. 1997;41:271-4.

Vidal VP, Chaboissier MC, de Rooij DG, Schedl A. Sox9 induces testis development in XX transgenic mice. Nat Genet. 2001;28:216-7.

Vining B, Ming Z, Bagheri-Fam S, Harley V. Diverse regulation but conserved function: SOX9 in vertebrate sex determination. Genes (Basel). 2021;12(4).

Wagner T, Wirth J, Meyer J, Zabel B, Held M, Zimmer J, et al. Autosomal sex reversal and campomelic dysplasia are caused by mutations in and around the SRY-related gene SOX9. Cell. 1994;79:1111-20.

Weber C, Zhou Y, Lee JG, Looger LL, Qian G, Ge $\mathrm{C}$, et al. Temperature-dependent sex determination is mediated by pSTAT3 repression of Kdm6b. Science. 2020;368:303-6.

Yamashita S, Kataoka K, Yamamoto H, Kato T, Hara S, Yamaguchi K, et al. Comparative analysis demonstrates cell type-specific conservation of SOX9 targets between mouse and chicken. Sci Rep. 2019;9:12560.

Yao HH, DiNapoli L, Capel B. Cellular mechanisms of sex determination in the red-eared slider turtle, Trachemys scripta. Mech Dev. 2004;121:1393-401.

Yuan H, Corbi N, Basilico C, Dailey L. Developmental-specific activity of the FGF-4 enhancer requires the synergistic action of Sox 2 and Oct-3. Genes Dev. 1995;9:2635-45.

Zhao L, Svingen T, Ng ET, Koopman P. Femaleto-male sex reversal in mice caused by transgenic overexpression of Dmrt1. Development. 2015;142:1083-8. 